\title{
Study for Organic Soybean Production Information Traceability System Based on Web
}

\author{
Xi Wang, Chun Wang, Xinzhong Wang, and Weidong Zhuang \\ College of Engineering, Heilongjiang Bayi Agrucultural University, \\ Post Code: 163319, Daqing, China \\ ndwangxi@163. com
}

\begin{abstract}
The paper analyzes the mode of organic soybean production supply chain and identifies the information needed to be recorded in each step of producing organic soybean through surveying the actual situation of organic soybean on the Red Star Farm combined with the mode of operation among enterprises, then it ensures integrity and consistency of information flow chain. At the same time, it establishes organic soybean production information traceability system, which adopts B/S architecture, ASP dynamic web technology and SQL Server 2005 database. By the system, enterprises can quickly inquire about the information of cultivation and processing of raw materials as well as the situation of products in time. Meanwhile, consumers can also inquire about the information of products by means of Internet quickly and easily, which enhances the transparency of production chain and ensures food safety.
\end{abstract}

Keywords: soybean, traceability system, internet, agriculture information.

\section{Introduction}

More and more people in our country even in the world have paid aettention to the topic of food quality since the 90 s of last century, along with a series of mad cow disease, hoof-and-mouth disease and bird influenza which made people feel fear greatly and gave destructive strike on the related industries like export obstacle, sales decline. China is a major exporter that has more exports to the European Union, the United States and other countries after it has joined WTO, it cries out for implementing product tracking and tracing in order to meet the food quality requirements of developed country, serve the export for better, avoid technical barriers, improve the quality of agricultural products and enhance international competitiveness. Therefore, it is very important to build products safety traceability system which can promote information security system, ensure the safety of consumable and enhance the competitiveness of our country ${ }^{[1]}$.

Taking organic soybean products which are produced by the Great Northern Wilderness People Organic Food Co., Ltd for example, it makes organic soybean production information traceability system true based on researching the process of organic soybean production and processing and analysis of tracing basic framework. The system can record information that related to product quality and safety while it 
produces and manages, which not only can supply the products information of quality and safety for consumers, but also quality control operations for business.

\section{Analysis of Organic Soybean Production Supply Chain}

The goal of analysis of organic soybean production supply chain is to enable producers to sell their products conveniently, making good quality and prices true and increasing revenue, enable administrators to understand the quality of products accurately in time, enable consumers to know product quality traceability and related information. It is meaningful to have the function of recording, transmission and management, which is good to improve products quality safety, increase the transparency of the whole process information and build products traceability system ${ }^{[2]}$.

\subsection{The Meaning of Soybean Production Supply Chain}

Soybean production supply chain refers to do some physical economic activities of soybean and its relevant information from producers to consumers in order to meet consumers' demand. It is the chain system that is composed of soybean growers enterprises and so on. Specifically, it is composed of seeding, fertilizer, stalks and labour control, mechanism management, harvest, processing and packaging, and making the soybean appreciated in the process.

\subsection{The Basic Structure of Organic Soybean Production Supply Chain}

Organic soybean production supply chain includes organic soybean plant, organic soybean processing, organic soybean packaging and so on. Every step is composed of different participants, among whom the constant distribution process makes organic soybean come true from planting, finished products to being bought by consumers at last, which makes up physical flow. In the process of distribution, participants from different steps send information to each other, which makes up information flow that has the characteristic of tracking and traceability.

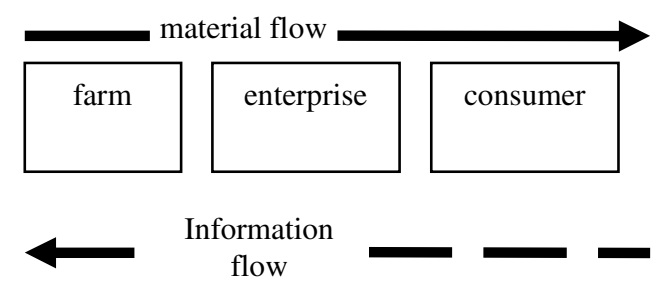

Fig. 1. Structural model of supply chain

Participants from organic soybean production supply chain.

(1)Organic soybean plant farmers: the process of production supply chain plant, which supply materials for organic soybean.

(2)Organic soybean processing enterprises: the process of supply chains processing, packing and marketing, especially processing. 


\subsection{Organization Modes of Organic Soybean Production Supply Chain}

Organization modes of organic soybean production supply are composed of participants that interact with organic soybean production and communicate with each other, moreover enable to finish its communication function. As participants play different parts in the organic soybean production supply chain, organization modes of organic soybean production supply chain become different. It analyses organic soybean organization modes according to Heilongjiang reclamation area based on agricultural standardized production, laying stress on green organic food, making processing industry as centre shaft, aiming for improving core competitiveness of Great Northern Wilderness Group.

Farmer or base $\rightarrow$ processing enterprises $\rightarrow>$ exports or marketing for wholesalers, retailers, processing agricultural products businesses export products which have been processed from our own base and farmer, or sell to wholesalers, or set windows for selling to consumer directly.

We must keep the information chain unblocked and integrated in order to achieve the need of organic soybean traceability. That means participants must keep detailed records about planting and processing, which can supply some information for quality problem and give consumers useful information. Participants of distribution step are responsible for recording the source of goods so that bad products can be recalled easily.

(1)Growing information: terrains numbers information, planting time information, planter information, the proposed crops information, soil information, seeding information, management information and harvest information.

(2)Processing information: crop source, time of arriving to factory, peeling processing.

(3)Packing information: traceability number, worktable, quality inspector, packing time.

(4)Products information: product name, production date, product strains, product specification, product categories, etc.

\section{System Design}

\subsection{Traceability System Function}

Traceability system does not provide quality assurance, because it is only good at tracking, without improving the quality of products. It can define responsibilities of each participant through recording information, then reducing the incidence of counterfeit and improving the quality of products.

Traceability system combined with management system methods can paly a stronger part, such as GMP, HACCP and so on. These quality management system has their own record systems, which provide a good foundation for enterprise interior traceability ${ }^{[3]}$.

\subsection{Development Platform}

Under the software engineering ideas guidance, the study collects a great number of planting and producing information and designs two functional modules which 
include the background information management system and the foreground information enquiry system combined with the basic theory and methods of agriculture and computer subject. The background information management system is responsible for recording, modifying and deleting information, the foreground information enquiry system is responsible for tracking information of quality, planting and growing. It establishes a network of organic soybean products traceability system through using ASP object-oriented dynamic page, SQL serve 2000 database and B/S system structure, the overall design framework as in figure 2.

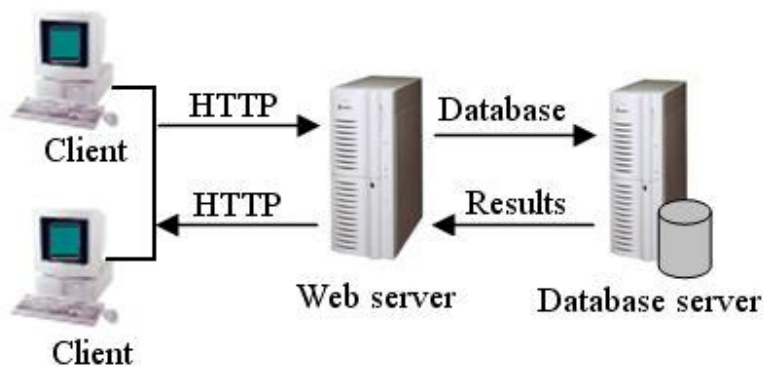

Fig. 2. Architecture of the B/S

\subsection{System Structure Design}

The modern organic soybean traceability system has built the perfect management system, including crop seeds, fertilizer information, artificial management, machinery management, diseases management, pests management, harvest management and so on, it makes electronic filing true from planting to harvest and from producing to processing. The system which inquire about planting information through management system focus on the process of planting and processing corps.

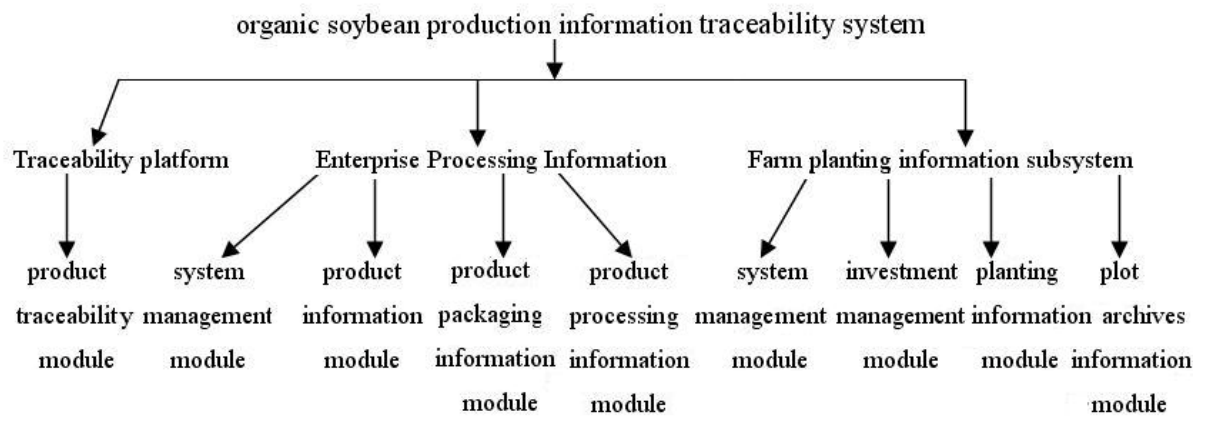

Fig. 3. The overall structure of the system function

Enterprises collect traceability information in detail, which can go back to the production process of each product. It can achieve functions by the query numbering system. 
(1)Farm can inquire about all the planting situation using terrains code.

(2)Processor can inquire about processing chain information through products code, and then goes back to the production process of each product.

(3)Consumers who are using web can inquire about producing information of all organic agricultural products through products traceability numbers, which can guarantee consumers' legitimate rights and interests.

\section{Key Technology}

\subsection{ASP Technology}

ASP (Active Server Pages), dynamic server page, including three parts of the content: VB Script or JavaScript scripts the code, which is used to implement the logical control; Integrated server functionality components, which is used to passing on a information of the client and server, $\mathrm{ADO}$ (ActiveX Data Objects, ActiveX), which is used to access the database.

\subsection{JavaScript}

JavaScript is a type of light and interpretation programming language and has ability of oriented object. The language common core has been embedded Netscape, Internet Explorer and other web browser, it makes web process design rich and colorful expressing the web browser window and its content object. The client version of JavaScript adds executable contents to the web, in this case, the web is not static HTML, but including the process of interacting with the procedures, the process of controlling browser and the process of building HTML dynamically ${ }^{[4]}$.

\subsection{ASP+ADO Database Access Technology}

ADO (ActiveX Data Object) a database access control of asp built in the server, it is the most efficient, simplest, powerful function method aiming at data operation that Microsoft software supports. It supplies database technology which can gain access to Internet easily for dynamic web page. ADO can supply main content including database information for users through accessing and operating data sheet in the database and can make user have access to background database through executive SQL command. In addition, ADO is almost compatible with all kinds of the database system, such as Microsoft Access, FoxPro, SQL Server and so on, ADO supplies the same mediashow for programmers ${ }^{[5]}$.

\section{System Operation}

Organic soybean quality security traceability system has been put in the actual application, including prevention crops pests query, organic agricultural products implementation standard query, organic crops production operation procedures query, prevention crops diseases query, organic agricultural products traceability system, etc.

Organic soybean product traceability system can make us understand traceability information of single product production supply chain from planting to processing and make tracking products true, which ensures the quality safety of products, in this 


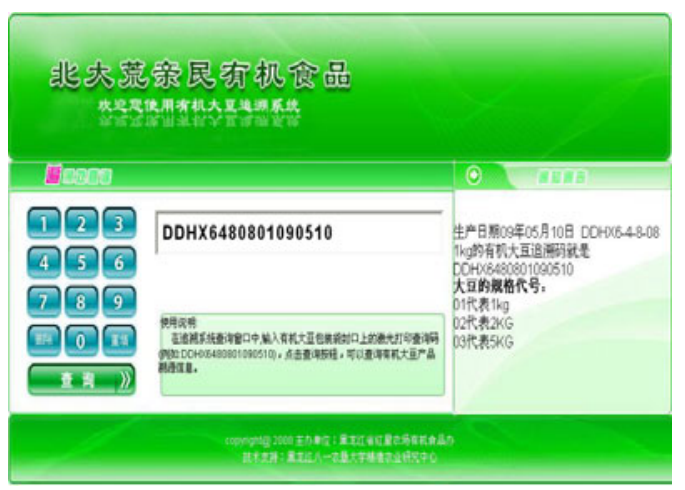

Fig. 4. Traceability information system of organic soybean

case, enterprises can inquire about materials information of production and inspection and understand the situation of agricultural production quickly. Consumers also can inquire about the information of products, it enhances the transparency of production and improves consumers' confidences. The red star farm organic soybean quality safety traceability information system, as shown in fig 3.

\section{Conclusions and Prospects}

It analyses organic soybean production supply chain concretely in the face of planting, harvest, processing and packing. combining with organic soybean production practice, it ensures the integrity of organic soybean quality safety information, which is good for tracking information, and it also supplies data supporting for organic soybean quality safety information platform. It put forward the structure of B/S organic soybean traceability system which makes system have better operation, security and stability.

The problem of food quality safety is still concerned by people at home and abroad. The implementation of digital information management is more and more popular with the spread and development of information technology, transparency of production information. It researches on the multi-factor of organic soybean traceability combining with the characteristics of Great Northern Wilderness organic soybean. Currently, the system only involves the parts from planting on the farm to processing in the enterprise, but in the future, the system can reach more fields such as selling field.

\section{References}

1. Shi, Y.: Agriculture Products Traceability System Study. Chinese Agriculture University, Beijing (2006)

2. Chen, H., Shi, Y., Tian, Z.: Game Analysis of Agriculture Products Traceability System in Our Country. China Economist (7), 10-12 (2007)

3. Geng, C.: Research on Agriculture Products Quality Security Information System Building. Shandong Agricultural University, Shandong (2006)

4. Wang, P., Feng, M.: Web2.0 Development of Technology Solutions, pp. 13-15. People Postal Press, Beijing (2006)

5. Sun, Q.: Implementation of Assignment System Based on Web Developed by ASP. Journal of Xuzhou Normal University (Natural Science Edition) (9), 25-28 (2001) 